\title{
Reflection on the role of physical education in the process of spreading sports culture
}

\author{
Junchao Bao
}

Dept. of PE, Wuhan Univ. of Science and Tech., Wuhan 430081, China

\begin{abstract}
Keywords: Sports cultrue, Physical Educationl, Colleges and Universities.
\end{abstract}
\begin{abstract}
Through the analysis of the content of physical education in ordinary colleges and universities, it is considered that there is a lack of sports culture in PE teaching. Sports culture has the important spirit of mediating the human spirit and concentrating the strength of the people. It is of great significance for ordinary colleges and universities to carry out sports culture education in the process of physical education. It is suggested that the physical education should promote the sports culture and put forward that the sports culture education should be separated from the traditional physical education teaching, and the sports culture should be taught by public compulsory, elective course or fixed lecture.
\end{abstract}

\section{Introduction}

Course Objectives Determine course content. In 2002, the Ministry of Education promulgated the "National Higher Education Plan for Physical Education Course Decisions" on the objectives of college sports curriculum has a complete statement, and "to achieve the objectives of physical education, classroom teaching and extracurricular, extracurricular sports activities (Social, field) activities, sports training and so on into the physical education curriculum, the formation of internal and external, both inside and outside the organic link between the curriculum structure of the school, the school, the school and the community in close contact with the purpose of a planned, organized, extracurricular physical exercise, ${ }^{[1]}$ "This means that the content of physical education in colleges and universities has a wide range of extrapolation, therefore, the choice of college physical education teaching content worthy of careful consideration.

\section{Definition of Sports Culture Connotation}

Sports culture not only includes sports and the necessary conditions for the realization of sports, but also contains the sports as a medium to produce the social psychological needs, that is, the spiritual level of sports culture. Sports culture has a very broad, complex content, which covers the theory of sports. It should be pointed out that the sports culture in this paper emphasizes the spiritual culture of the spiritual level, while the sports theory mainly refers to the basic sports knowledge taught to students in physical education, including basic technical skills tactics, rules and referees Law, basic rehabilitation health knowledge, scientific exercise principles and methods.

\section{Lack of sports culture in sports teaching content}

The content of physical education teaching is not only the most important part of physical education, whether it is in the military national sports values, physical education view, competitive sports values or people-oriented physical education values ${ }^{[2]}$ People master life skills, the production of labor skills of a training. The new "outline" clearly sets the course's athletic skills Objective: "master the basic methods and skills of two or more fitness exercises; can carry out physical exercise in a scientific way and improve their athletic ability." And more and more people realize participation movement and in the movement to accelerate the "socialization" [3], therefore, the college physical education reform to an extreme, that is, the teaching of sports skills to become the general college PE teaching all. Soccer, basketball and volleyball are the most popular projects in the teaching of skills, badminton, table tennis 
and other traditional Chinese advanced projects have become the hot choice of skills teaching, tennis, aerobics, directional off-road, rock climbing and expansion and other emerging sports projects have become teaching Fashionable pursuit, and China's traditional sports, Western leisure sports are also being further excavated, a variety of school-based curriculum is also constantly developing a variety of sports programs. For a time, it seems that the development of sports more and more can able to reflect the depth of its reform. It is undeniable that the development of these projects has a very important value and role in making full use of various curriculum resources, sports facilities resources, sports project resources and natural environment resources, etc., to alleviate the lack of facilities in our sports venues, enrich the teaching content and speed up the course content structural adjustment plays a key role. The development and utilization of these sports projects is also an important part of the reform of college physical education curriculum in our country. But focus on the development of sports and sports skills teaching at the same time, the corresponding sports culture teaching is ignored, and this phenomenon intensified.

Because of the particularity of physical education teaching, especially the practice of teaching mainly in the sports venues, according to the basic law of physical education, in the acquisition of motor skills as the main task of teaching, only possible to carry out some of the necessary sports theoretical knowledge, For sports culture, especially the spiritual level of sports culture can not be involved. Especially in the focus on training students "body" at the same time, but ignored the students "heart" of the mold. Resulting in a lot of people in the university during the sports knowledge on the work after the sports have no effect ${ }^{[4]}$.

With the deepening of teaching reform in colleges and universities, the construction of sports quality courses has become the basic core work of college physical education teaching reform and basic construction. Its quality and achievements have become an important symbol to measure the quality of college physical education ${ }^{[5]}$. However, the construction of sports excellent course must also be based on the current diagnosis and analysis of the current physical education curriculum, especially on the defects and shortcomings of the current physical education curriculum criticism ${ }^{[6]}$. Therefore, no matter how the teaching reform changes, sports education in general college physical education should pay enough attention.

\section{The Significance of Physical Education in Physical Education in General Colleges and Universities}

Sports culture is a necessary basis for deep understanding, identification and interpretation of various sports phenomena. The way in which modern students get information is increasingly diversified. Students are no longer satisfied with the athletic skills learned from the physical practice classes. They will pay more attention to their favorite sports and hot sports events, Appreciation, and even insightful evaluation, which requires a considerable sports culture. Not only to understand the project rules, game style and tactical system, but also understand, appreciate and even experience the movement through the human spirit and sports spirit. As the saying goes: "layman to watch the lively, insiders watch the door." Only the sports culture has a comprehensive understanding and mastery, can calmly deal with a variety of sports, explain the various sports problems, and in the process of continuous understanding and Improve the sports culture knowledge, the formation of a virtuous circle, in order to achieve the infinite charm of the movement to achieve the "heart" of the mold.

The study of sports culture and understanding can promote the prosperity of sports culture. Sports culture, not only to learn competitive sports culture, but also concerned about the traditional sports culture, leisure sports culture and emerging sports culture, concerned about the Olympic culture and other major countries, regional sports culture, and different sports culture conflict and blending The As we all know, the mainstream sports culture in our country and even the whole world is the western competitive sports culture represented by the Olympic culture. We have inadvertently become a cheap communicator and advocate, and our traditional sports culture has become a weak culture. Only to a variety of sports culture in front of students, so that students choose their own, in order to promote the 
development of sports culture, transformation and innovation in order to appear sports culture "one hundred schools of thought" prosperity.

Sports culture to observe the spirit of people, cohesion of human strength. Sports has penetrated into every corner of modern society, the impact of sports on the human body not only in the human body to complete the shaping of people, more importantly, the spirit of sports culture and its philosophy in the heart of people With the subtle influence of the guiding role, this sports culture embodies the voice of the times, and with the inner feelings and values of the formation of sympathy ${ }^{[7]}$. The Beijing Olympic Games will be held so that the Chinese humanistic spirit and harmonious spirit will spread throughout the world. It will show the world of Chinese sports culture and realize a long history of Olympic culture and a great exchange of Chinese civilization. It is bound to break the regional culture of sports culture Restrictions, so that people around the world to enjoy the traditional Chinese sports culture, but also to promote the Chinese national sports culture in the Olympic movement in the release, dissemination and development.

Sports education in general colleges and universities has a very positive significance for enriching campus culture. Campus sports culture in the campus culture is a profound connotation and rich extension of the unique cultural phenomenon, it is a college campus characteristics and healthy living atmosphere of a mass sports culture. Campus sports culture has a high level and taste, is a set of sports, fitness, entertainment, recreation, aesthetic, communication and other functions in one, reflecting the campus culture and spiritual civilization window. It covers far more than physical education and sports activities can be anywhere in the school, especially in the hostel to watch, comment on the Premiership, Serie A, NBA and so on. This process of watching, listening and talking is the process of thinking about the students' thinking, and any depth, identity of the comments are based on the corresponding sports culture on the basis of mastery. To the profound cultural background as the background of the comments are more conducive to the spread of sports culture is extensive, profound and valuable. College sports is the last part of school sports, it is the key point of school sports and social sports convergence, will be an important component of social development, but also a direct participant in mass sports ${ }^{[8]}$. Sports culture plays an important role in guiding and nourishing all aspects of students' individual spirit, campus culture and social life. Therefore, the general college physical education, sports culture education is very necessary.

\section{Summary}

Physical education curriculum not only reflects the country's specific sports culture, but also responsible for the responsibility of transformation and innovation ${ }^{[9]}$. China's current general college physical education curriculum type generally includes basic courses, elective courses, during which contains $10 \%$ of the hours of theoretical courses, health classes and elective courses. The teaching content is: basic course to teach fitness methods and enhance physical fitness as the main task; elective course focus on student interest training and athletic ability, give full play to personality; health course mainly for defective students, health care knowledge and suitable sports As the main teaching content; elective courses are further to the movement of technical skills to learn and improve the main, while strengthening the physical exercise. In the technical skills to learn at the same time, the necessary theoretical knowledge of sports. China's general college sports theory teaching, whether it is teaching hours or teaching content, form and methods are urgent to be improved. In this situation, the new "outline" arrangement of about 10\% of the theoretical teaching content (about 4 hours per semester), from the previous $12 \%$ further reduced to $10 \% .4$ hours of theoretical courses can only be carried out in sports practice in the basic theory of sports necessary to sort out and supplement, and sports culture teaching is no time to take into account. How to carry out sports education in general college physical education is a new topic in front of us.

In the current physical education curriculum system, has been unable to expand the content of such physical education in the provisions of the class time. The sports culture alone out, arrange a certain class, the public compulsory or elective course in the form of all students; or sports culture as a quality 
education, moral cultivation or general education, included in the overall plan of school sports, In a number of lectures in the form of regular display in front of students, so that students in the vast culture of sports culture in the emotional experience and sublimation. Only so, in order to achieve the physical education "practice" and "education" and "and" to achieve the comprehensive development of sports "harmony".

\section{References}

[1] Ministry of Education. National general college physical education curriculum to understand the outline [M]. 2002, (12).

[2]Jiang Yu. Retrospection and Analysis of the Values of Physical Education Curriculum in China[J]. Journal of Wuhan Institute of Physical Education. 2007, 41 (1): 78-81.

[3]Lai BinShen. Research on the Content System of Physical Education Curriculum in Colleges and Universities [J]. Journal of Sports and Science. 2007, 28 (2): 79-82.

[4] Ministry of Education directly under the comprehensive university physical education. China's university sports reform review and outlook [M]. Beijing: Beijing Sports University Press, 2001.

[5]Dou Zhongxia.Sports curriculum microstructure and sports quality course construction [J] .Shanghai Institute of Physical Education, 2007, (31) 2: 80-83.

[6] Feng Wanling, et al.Study on the Construction of Excellent Course in Colleges and Universities [J]. Education Research, Tsinghua University, 2006.27 (2): 115-118.

[7]Yang Wenxuan,et al. The role of sports culture in human cultural transformation [J]. Journal of Sports Culture, 2006,6.

[8]Yue Jun. The Construction of College Physical Education Curriculum System from the Perspective of Mass Sports [J]. Education and Occupation, 2007,3: 128-130.

[9] Huang Aifeng, et al. Cultural examination of physical education curriculum reform [J]. Journal of Tianjin Physical Education Institute, 2004,19 (2): 4-6.

[10]Zhang Xuelin, et al.Chinese significance of humanistic spirit and harmonious spirit of Chinese sports culture [J]. Journal of Sports and Science, 2005,26 (5): 27-29. 